\title{
Investigation of oil pollution on aquatic animals and methods of its prevention
}

\begin{abstract}
All the factors that cause oil pollutants to enter the sea in some way, can cause water and sediment pollution. Oil pollution in the seas in the plant and animal communities and marine ecosystem, has destructive effects and in the meantime has acute effects on fish and effects. It has been observed in the larval and juvenile stages of fish as well as genetic damage to them. Hydrocarbons are quantitatively the most important constituents of oil that arise from natural as well as human resources. Petroleum pollutants as a major threat to marine ecosystems It is considered that one of the most basic ways to deal with these contaminants is to use methods that can significantly reduce this contamination. Considering the important effects of oil pollution on the marine and aquatic ecosystem, in this article we will explain about this pollution and ways to prevent it.
\end{abstract}

Keywords: marine ecosystem, petroleum pollution, hydrocarbons, biodegradation
Volume 9 Issue 5 - 2020

\author{
Elmira Norouzi Loyeh, Reza Mohsenpour \\ Department of Fisheries, University of Guilan, Iran
}

Correspondence: Reza Mohsenpour, Department of Fisheries, Faculty of Natural Resources, University of Guilan, Iran, Email reza.mohsenpour5@gmail.com

Received: August 18, 2020 | Published: September 28, 2020

\section{Introduction}

Petroleum compounds and their depletion effects on living species in marine environments have drawn attention to the problems caused by point pollution in aquatic ecosystems. According to studies, about six million tons of oil enter the environment annually, including hydrocarbons such as light hydrocarbons. Crude oil is a polycyclic aromatic hydrocarbon and the like that flows into the seas and oceans. Hydrocarbons are the most important constituents of oil in terms of quantity and arise from natural as well as human resources. ${ }^{1}$ Petroleum hydrocarbons are important organic elements and have attracted a lot of attention because many of them are effective in biological processes and genetic abnormalities, are toxic and carcinogenic. ${ }^{2}$ Many factors, such as local currents, air and water temperature, and the composition of the oil itself, affect the long-term degradation caused by large oil slicks compared to other factors. The effects of oil pollution in water can be divided into two types, long-term and short-term. These layers, in addition to reducing light transmission, inhibit the photosynthesis of aquatic plants and greatly slow down the absorption of oxygen from the air by water. So that the rate of oxygen dissolution in the aqueous layers of oil slicks is even less than deep water layers. ${ }^{3}$ One of the best ways to deal with this pollution is to find a way to significantly reduce it, which requires a thorough understanding of oil and hydrocarbon pollution and the effects it has on the marine ecosystem. These cases have been investigated.

\section{Impact of oil pollution on health and ecosystem}

Crude oil, due to its special chemical properties, causes serious damage to human health and ecosystems. Prolonged presence and high concentration in the environment causes kidney disease, liver and various cancers. ${ }^{4}$ In general, aromatic compounds are more toxic than aliphatic compounds, and low molecular weight compounds are more toxic than high molecular weight compounds. Sunlight affects the toxicity of oil and the surface of oil exposed to light is less toxic than water-soluble parts. ${ }^{5}$ Polycyclic aromatic hydrocarbons are highly toxic pollutants and can pass through the skin., Breathing, swallowing and food chain enter the human body. Their primary effects are shortness of breath, dry cough, chest pain, and irregular heartbeat. It is also the most toxic in crustaceans in marine environments and is absorbed and accumulated in some marine plants and animals. ${ }^{6,7}$

The different effects of oil on living organisms are dependent on the level of pollution and periodic evaluation and monitoring of pollution is necessary for the management of polluted ecosystems. ${ }^{8}$ Levels are higher. Petroleum hydrocarbons affect the semi permeability of membranes by displacing lipid compounds, inhibiting photosynthesis and impairing the growth and reproduction of phytoplankton. This is due to the dissolution of chloroplast lipid-phase hydrocarbons and interference with the interaction of chlorophyll molecules. Another similar disturbance occurs in the mitochondrial membrane, causing a tri-carboxylic acid cycle and oxidative phosphorylation. Cosine diverts cell membrane lipids and then infects toxins in red seaweed, and naphthalene also reduces cellular protein levels. Oil also inactivates the feeding duct in echinoderms, causing cancerous masses in the mouth of fish and burning of the eyes. The effects of oil on birds include the infiltration of oil into their feathers, the replacement of water with air, the loss of thermal insulation and reduced buoyancy, and birds will not be able to swim and fly. Also, the toxicity of oil reduces the viability the eggs. ${ }^{9}$

Low levels of oxygen and saturation of sediments with water, mangrove forests, reduce oil decomposition, and especially aromatic hydrocarbons in these areas remain and accumulate for years and can even last up to 20 years. In mangrove forests, floating oil suffocates the respiratory and nutritional roots and not only destroys some trees, but also reduces the growth of trees, but also reduces the growth of the remaining trees. The shape of the fruits shows the effects of the loss of their cover. ${ }^{10}$

\section{The ecological effects of oil pollution depend on several factors}

1. Type of oil: The type of oil and how the physical and chemical properties of oil and its derivatives determine the dangerous degree of oil leaked in water. Hydrocarbons (H-c), which make up $95 \%$ of petroleum compounds, are considered toxic 
oil agents and are partially dispersed in water dissolved in the water column. Aromatic hydrocarbons, which are highly volatile and volatile, evaporate very quickly in the air. The higher the solubility of crude oil in water, the greater the degree of toxicity.

2. Atmospheric conditions and oceanography: Atmospheric conditions are effective in the natural oxidation of oil (spontaneously). The temperature of the seawater is effective in this self-purification so that the oil pollution in the waters of Antarctica due to the cold water can remain for up to 50 years.

3. Physical geography of the area

4. Water rotation and seasons

5. The presence of other contaminants

6. The types of life of plants and animals in that area

7. How to settle and the amount of oil that may occur in two ways:

A. Sudden leakage (due to collision and the like).

B. Continuous leakage of waste of an industrial unit, etc.

Some of the negative effects of oil pollution can be summarized as follows:

1. Interference in the movement of living organisms that lead to drowning or freezing.

2. Acute toxic effects due to aromatic compounds with low boiling point that lead to immediate death.

3. Fatal effects due to components with high boiling point that affect physiological and behavioral stages They put.

4. Changes in the physical and chemical environments that lead to changes in individual populations as well as changes in the composition and variety of these animals.

\section{Toxicity of crude oil}

Crude oils contain a wide range of toxic substances such as gasoline, toluene, xylene and other light aromatics. In addition to acids, phenols and sulfur compounds (such as sulfides, etols and etophenes) PAHs (such as 1 and 2 benzanthracene, 3 and 4-benzene Pyrenees, 1 and 2 benzphenatrans, diphenyl methane, fluorine, phenatrans. Among the hydrocarbon components, smaller molecules become more toxic. The toxicity of paraffins to naphthenes, olefins and aromatics increases, respectively. They are the most toxic and evaporate the fastest Therefore, during the first 24 hours to 48 hours when an oil slick is dumped in the sea, the volatile components with a lower molecular weight (lighter) evaporate easily from the crude oil. This loss is due to hydrocarbon evaporation. Transactions significantly reduce the total crude oil in the sea. As a result, its potential impact on marine ecosystems is reduced.

\section{Components of crude oil}

Crude oil is made from a combination of carbon and hydrogen and contains sulfur, oxygen, nitrogen and metals, which are approximately as follows:

\section{Carbon $87-84 \%$}

Hydrogen $14-11 \%$
Sulfur 5-0\%

Nitrogen $1-0 \%$

Oxygen $1-0 \%$

Crude oil is divided into three categories: paraffinic, naphthenic and asphaltic.

Hydrocarbons in crude oil include three categories:

A. Aliphatics, alkanes, alkenes, alkynes

B. Alicyclics: cycloalkanes, cycopentene, cyclohexane, cycloheptadine, etc.

C. Aromatic: benzene, anthracene and toluene and...

Crude oil also contains metals such as nickel and vanadium, which are mostly found in crude oil, but iron, zinc, cream, copper and manganese, and cobalt are almost always present in the oil. Some metals are present in the form of salt (salt) and calcium, which is obtained from water with oil.

\section{Hydrocarbons}

Hydrocarbons are the main component of crude oil. Their molecules are only carbon and hydrogen. Petroleum hydrocarbons enter the water basin of the Caspian Sea through the reverse flow of water of the Caspian Sea, the main rivers supplying the lagoon, as well as due to leaching and leakage of gasoline from the marine tank engines. Therefore, these hydrocarbons are able to pollute aquatic animals through environmental pollution. In addition to contaminating aquatic animals, the above compounds are also transmitted to humans through the food chain. Due to the accumulation (according to the European Union, the permissible amount of fluorine, phenanthrene and anthracene is 20 micrograms per dry weight) of these compounds in the human body, consumption of these fish may cause symptoms of poisoning in the human population, especially children. ${ }^{3}$

The compounds fluorine, phenanthrene, and anthracene are composed of hydrogen and carbon atoms in the form of two or three aromatic benzene rings, which are joined together in a cluster or at an angle. This group is very toxic but has little carcinogenicity. ${ }^{2}$ Aromatics and other light petroleum hydrocarbons, despite their high toxicity, are converted to steam in the early hours of the leak and enter the atmosphere. While heavy hydrocarbons show a tendency to settle in wetland sediments. Heavy petroleum hydrocarbons are less toxic in terms of severity of pollution with light petroleum (aromatic) hydrocarbons, but due to the presence of these compounds in the wetland bed, the stability of this type of compounds, fluorine and anthracene, which have the highest frequency and concentration in water and sediments. They have the highest abundance in this species of fish. This point indicates that the three-ring compounds also enter the body of fish through feeding on benthic organisms and accumulate in their edible texture. ${ }^{3}$

Sources of hydrocarbons that cause seawater pollution can be classified as:

1. Drilling and oil extraction operations near coastal waters

2. Ship operations, including washing, cleaning the bottom of tanks, draining the balance water, etc.

3. Accidents related to tankers

4. Offshore oil refineries and facilities and petrochemical plants 
5. Disposal of municipal and industrial waste

6. Boating recreation areas

7. Natural oil springs

8. Sediments and dust

\section{Crude oil metals}

There are different metals in the composition of crude oil, which we will explain in relation to some examples:

Lead: Lead in combination with sulfide groups of proteins and especially enzymes involved in the production of molecules also disrupts the Na-K ATPase pump from the red blood cell membrane. This leads to a reduction in their lifespan, chronic nephritis, myocarditis, neurotoxicity, placental abruption and premature rupture of the amniotic sac (PROM) and eventually premature delivery and consequently premature infants. It will cause some poisoning and absorption of $0.5 \mathrm{gr}$ will also cause death. ${ }^{11}$

Lead can accumulate in the body and, when in the form of dualcapacity lead, can replace calcium ions in bones. This substitution allows lead to remain in the body for a long time. ${ }^{12}$ According to Clark studies, lead toxicity to marine organisms is lower than that of other metals in the sea, and at concentrations above $0.8 \mathrm{ppm}$, lead nitrate increases the growth of phaeodactylun diatoms through the nutritional effect of nitrite. ${ }^{13}$

Cadmium: Cadmium is a pollutant whose penetration into the water can be due to the use of chemical fertilizers (phosphate fertilizers) in agricultural activities, polluted atmospheric sediments from industrial plants and the discharge of industrial activities or mines. Although cadmium is present in very small amounts in water, its excessive accumulation can cause diseases such as prostate cancer, high blood pressure, destruction of testicular tissue and red blood cells, clogged renal ducts, coagulation of some proteins and disease. Itayatia be accompanied. Cadmium is definitely a dangerous contaminant of water resources and it is very difficult to clean the contaminated water. ${ }^{14}$

Chromium: Chromium is a toxic element and its toxicity depends on its chemical forms; Hexavalent chromium is much more toxic to marine organisms than trivalent chromium and can easily cross cell membranes. Biological and non-biological factors increase hexavalent chromium, which can increase the toxicity of this element in seawater.

Mercury: in the environment by agricultural activities (fungicides and seed preservatives), pharmaceutical factories, as a preservative for paper and pulp, catalysts in the synthesis of organic matter, in the production of batteries and thermometers in the production of metal mixed with mercury and in Chlorine profit-making plants are abandoned. It is estimated that the annual inflow is 40,000 to 50,000 tons in the atmosphere and approximately 4,000 tons in the sea. Mercury toxicity depends on its chemical form (organic, metallic, and ionic). Mercury is mainly present in fish in its organic form, or dimethyl mercury.

Copper: The ability to transport copper in nature is much lower than that of zinc and cadmium. Low-density copper is not toxic to humans and is an essential element for living organisms. The main source of copper is oyster, which is found in the gastrointestinal tract and their kidneys accumulate. The average amount of copper in fish muscle is $0.5-0.5 \mathrm{mg} / \mathrm{kg}$ of wet weight, while the organs that have more copper include the liver, scales, anal, kidney and gills, respectively. Excess on the aquatic need for copper is stored mainly in the liver. ${ }^{15}$
Zinc: Zinc, like copper, is an essential element for humans and is a major component of enzymes. Zinc is commonly present in fish and other seafood in milligrams per kilogram, and no amount has been reported in fish edibles that could pose a risk to human health. The average amount of zinc is $3-5 \mathrm{mg} / \mathrm{kg}$ based on wet weight, and fresh fish is the most important source of this essential metal for humans.

\section{The most important organs in the body of fish are infected}

Gills, kidneys and liver are the most important ways of absorbing metals in the body of fish. ${ }^{16}$

The absorption of cadmium through the gills is much greater than the absorption through the gastrointestinal tract. Muscle tissue usually has the lowest amounts of heavy metals in fish and these elements accumulate in tissues such as kidney, liver and gills. ${ }^{17,18}$ The amount of mercury in the internal organs of fish is slightly higher than muscle tissue. ${ }^{19,20}$

Liver: The liver is the organ that is most associated with detoxification and biodegradation processes. Due to this function and the presence of abundant blood in it, it is one of the organs that is most affected by contaminants in water. ${ }^{6}$ It is important to select the liver as a biological indicator of environmental pollution, including that the liver of fish has functions such as inactivation of petroleum hydrocarbons, storage of nutrients and release of catabolism products of other tissues to produce bile, which plays an important role. It is very effective in digesting fatty acids and excreting toxic metabolites. It is very effective in maintaining and homeostasis of the body. Bile produced by hepatocyte cells is produced and secreted into the gallbladder. Toxins in the liver are refined from the blood and neutralized into other compounds and excreted and excreted into the intestine along with bile. The liver is also vulnerable to contaminants and chemicals due to its relatively slow blood flow compared to the heart. The rate of bile flow in fish is approximately 50 times slower than in mammals, which may contribute to the fish's greater susceptibility to chemical damage, as low bile speeds lead to slower excretion of metabolites and toxic chemicals from the liver. ${ }^{21}$ The blood it receives has the greatest effect on the contaminants in the water, and in general, several factors can cause liver damage, which due to the metabolic functions of the liver, such injuries can have serious effects on aquatic metabolism. ${ }^{22}$

Kidney: The kidney of a fish is located in an extraperitoneal position on both sides of the spine and is a brown to black organ. The kidney is divided into two parts: the anterior part which consists of hematopoietic elements (hematopoietic) and the dorsal part which is excreted. Is. The most important function of the kidneys in fish is the osmotic regulation of water and salt through the excretion of excess nitrogenous substances, which plays an important role in maintaining the body's homeostasis. They are responsible for various xenobiotics. Therefore, the kidneys are constantly exposed to chemical toxins and their dangerous effects and are an important target organ for many environmental pollutants. ${ }^{23}$

Gills: Fish gills are the main site of gas exchange in almost all fish. The gills of fish are made of hard bony or cartilaginous arches and are protected by a gill skull. Most fish exchange gas using gills on either side of their throats. Gills are tissues that look like short threads. They are exposed to contaminants such as pyrene, hyperemia, and s-shaped blades. Exposure of this organ to various levels of contamination by Pyrenees causes it to become deformed, shortened, clubbed, and torn off. ${ }^{24}$ 


\section{The impact of oil pollution on different communities of plants, animals and aquatic animals}

\section{Effect of oil pollution on plant communities:}

A. Phytoplankton in marine ecosystems contaminated with oil Petroleum hydrocarbons immediately after release on the surface of the water reduce the penetration of sunlight to the depths of the sea by up to $90 \%$, resulting in photosynthesis by phytoplankton. (Due to the photosynthetic action of phytoplankton, they are very important.) Naturally, phytoplankton organisms are severely damaged by oil pollution, and because these organisms reproduce directly, oil spills have short-term adverse effects on the planktonic community is in that area and the damage from other areas is compensable.

\section{B. Sea urchins or algae}

Petroleum-soluble compounds have adverse effects on algae, disrupting the electron transfer system and attaching to phosphorylation bonds. Petroleum compounds interfere with the physiology of algae by crossing the cell wall and preventing their division and growth turns.

Seaweeds in the tidal zone are highly exposed to oil pollution, while the QiQntkep-covered bed is almost safe from oil pollution and protects subtropical plants and animals from oil contamination due to oil pollution in the TomplicoMaru and Torreyc they are removed. Red algae are one of the most sensitive algae to oil pollution and are generally eliminated.

\section{The effect of oil pollution on animal communities:}

Effects of oil on phytoplankton communities that feed on zooplankton destroy algae. Increasing petroleum content by $0.1 \mathrm{ml} / 1$ can destroy all animal plankton within 24 hours. Biomass of zooplankton is severely reduced by oil pollution.

Zooplankton, including duplicates, protozoa, can consume oil particles without any modification. The study shows that oilcontaminated volar fish eggs (planktonic conditions) have been found to have adverse genetic effects. The ill effect causes them to die.

Fish

One of the obvious signs of oil pollution is the bad taste of fish meat in very low concentrations of petroleum products, about 0.02 units per thousand. One of the abnormal effects of oil pollution: disturbing and reducing the fertility of fish and leaving their natural habitats as well as changing their behavioral states. Petroleum products and their derivatives enter the body of aquatic organisms through the food network and accumulate in the liver and gallbladder. ${ }^{25}$

Swallowed petroleum products enter the stomach directly and are excreted in the urine, fish feces, in the contaminated environment after consumption. The surface of the gills is covered with petroleum products and the impossibility of exchanging oxygen and carbon dioxide gases between the blood and air leads to suffocation. ${ }^{26,27}$

Most of the damage caused by oil pollution affects young and mature fish communities that live in shallow water. Studies have shown that fish caught contaminated with light petroleum compounds have undergone genetic modification, skin cancer and gill cancer.

\section{Mollusks}

In marine ecosystems, those aquatic organisms that live in the tidal zone suffer the most damage. Petroleum hydrocarbons, which contain toxic compounds, are deposited on the beach in the first hours after a spill, or cause respiratory distress, causing mortal mortality.

In general, oysters are resistant to oil pollution and protect their oyster shells in unfavorable living conditions and continue their life by having the ability to remove petroleum substances from the body with favorable environmental conditions.

\section{Crustaceans}

Crustaceans such as lobsters and carp are usually not directly exposed to oil contamination. The presence of a low concentration of $5.92 \mathrm{ml}$ of petroleum products in seawater changes the behavior and anorexia of adult crabs and lobsters. The lethal concentration of larvae and crabs is between 20 and 30micrograms per milligram per milliliter of petroleum compounds. Crabs are resistant to oil pollution at all stages of growth, but mating susceptibility is reduced in the contaminated environment.

\section{Methods of dealing with oil pollution}

\section{Physical methods}

Most common methods of dealing with oil spills in marine environments are physical and chemical methods. These methods are usually selected based on oil spill conditions, the type of ecosystem, as well as public opinion and political decisions. Physical methods for clearing oil spills are simple methods and include: using spatulas, washing, adsorbents and incineration. ${ }^{28}$

\section{Spatulas}

The use of floats with the help of spatulas to control the flow and movement of oil and then collect oil from the water surface into the tank is simple, low risk, and effective and $80 \%$ of leaked oil is recovered but its performance only in environmental conditions. It is quiet and is not effective in recycling high viscosity oil..$^{28,29}$

\section{Wash}

Washing is another physical method that uses hot or cold water and high or low pressure, depending on the current situation and can be used for coastal areas. ${ }^{28}$

\section{Absorbents}

Adsorbents are another method in which hydrophobic materials are used to remove oil pollution along the coast, in which adsorbents, in contaminated areas, facilitate the change of liquid phase to semisolid. Absorbents are divided into three groups: inorganic materials, synthetic organic materials and plant organic materials. Inorganic materials include: pearls, silica particles and clay adsorbents. These materials do not have sufficient buoyancy and their oil absorption capacity is generally low. Synthetic adsorbents include polypropylene and polyurethane foams and are widely used due to their hydrophobicity, but decompose very slowly compared to minerals or plants. Organic plant sorbents such as straw, wood fiber and corn wood have poor buoyancy and low adsorption capacity. Silk scraps have a high adsorption capacity because they contain a high wax content and have a porous structure. One gram of them absorbs approximately 40 grams of light crude oil at room temperature ${ }^{30}$ Small oil is used and if used before the oil pollution reaches the shore, it can limit the effect of 
spilled oil ${ }^{31}$ another type of adsorbents are biopolymers that are used to cover the surface and to prevent oil adsorption on surfaces. ${ }^{32}$

\section{Burning on the spot}

Incineration is a method used to remove oil residue after using spatulas. This method uses the least equipment and manpower and its efficiency is $95 \%$, but nitrogen and sulfur from burning oil enter the atmosphere and cause acid rain. The resulting smoke contains fine particles, PAHs and chemicals that are dangerous for those responsible. It also destroys vegetation and harms animals in the area. In fact, this method converts pollution from one type to another. ${ }^{29}$

\section{Chemical methods}

Dispersion is the breaking down of oil and its transport in the form of small particles from the surface to the air, which is controlled by the flow of the sea surface, and in more turbulence, more dispersion takes place. Chemical diffusers are built to speed up this process and are the lagoon and the first line of defense against oil spills. Sensitive beaches and habitats such as salt marshes of mangrove lagoons are treated with this method and because the dispersed oil particles are placed on the surface, they are more exposed to biosorption and the rate of biodegradation increases. ${ }^{33}$ The dispersant contains surfactant. It causes the oil stain to break and turn into micelles, which are easily diluted. ${ }^{28,34}$

Dispersers are divided into 3 main types: The first type contains $15-$ $25 \%$ surfactant and is sprayed on oil in a ratio of $1: 1$ or 3:1 (diffuseroil). The second type is in the form of alcoholic or glycolic solvents and contains a high concentration of surfactant and is diluted in a ratio of 10:1. The third type are concentric diffusers with the same formula as the second type and are diluted in a ratio of 5:1 and 30:1. The naturalness of the sea is sufficient for its function. The main advantage of diffusers is that it prevents oil from moving to sensitive shores and the formation of bituminous bullets. Among the disadvantages of this method is the possibility of toxic compounds entering the environment. Also, treating oil spills with diffusers creates oil droplets that are small in size and can be eaten by marine animals and enter the food chain and consumed by humans. Other chemical methods include the use of solidifiers and anti-emulsifiers. Which are a thin surface of chemicals that cause the oil to solidify and make it easier to physically clean the shoreline. ${ }^{28}$

\section{Natural methods}

When oil falls into the sea, it changes over time due to the effects of waves, sunlight and microbial activity, and some of the oil compounds are dispersed in the water column. While others are deep-seated through sedimentation and can also affect benthic plants. ${ }^{35,36}$ Because hydrocarbons are a source of carbon and energy, microorganisms can consume them. ${ }^{30}$ Bacteria that break down hydrocarbons make up $90 \%$ of the microbial community in oil spills. Marine organisms are very diverse in comparison with soil types and due to the production of special compounds, in the method of competition and evolution, have unique protective mechanisms. ${ }^{31}$ Mixed microbes are able to degrade high levels of contaminants. ${ }^{37}$

\section{Purification or bioremediation}

It is a relatively new method that uses the natural ability of microorganisms to reduce the concentration or toxicity of various chemicals such as petroleum derivatives, aliphatic and aromatic hydrocarbons, industrial solvents, pesticides and metals, and its most important feature is that in the environment. Non-sterile openings with a variety of microorganisms. ${ }^{37,38}$ Biodegradation is an important way to eliminate the leakage of petroleum hydrocarbons in aquatic environments and in recent decade's marine bacteria with the ability to decompose hydrocarbons from different places. The world is divided. The most important principle in bioremediation is the use of native marine microorganisms in the contaminated area that are able to survive and continue to operate in the natural conditions of the area. ${ }^{39}$ The type of polluted beach, the content of nutrients (nitrogen, phosphorus and oxygen) and $\mathrm{pH}$ should be examined. ${ }^{32}$ In addition to the above methods, there are other methods of using other substances that fight oil pollution, such as: Use of bio surfactants, various enzymes, saturated and aromatic hydrocarbons, asphalting, etc. ${ }^{40-42}$

\section{Conclusion}

Oil pollutants are considered as a major threat to the environment and its living organisms that enter the sea through various ways such as natural oil leakage from the sea, maritime transport, oil refining, etc. Oil pollution of the bacosystem the lives of aquatic and benthic organisms are endangered due to this pollution, and many of them have died. At the water level, the possibility of oxygen exchange is reduced and the percentage of some heavy metals in the body of living organisms is increased (so measuring the amount of heavy metals in various vital organs of aquatic animals is very important because it can have irreparable health risks for humans). Due to the importance of preserving the country's aquatic ecosystems and the health of marine proteins and the economy, it is necessary to work to reduce marine pollution as well as to deal with this pollution (one of the best ways to deal with oil pollution is biodegradation).

\section{Acknowledgments}

None.

\section{Funding}

None.

\section{Conflicts of interest}

The author declares that there is no conflicts of interest.

\section{References}

1. Deb SC, Araki T, Fukushima T. Polycyclic aromatic hydrocarbons in fish organs. Marine Pollution Bulletin. 2000;40(10), 882-885.

2. Watanabe K. Microorganisms relevant to bioremediation. Current opinion in biotechnology. 2001;12(3):237-241.

3. Clark RB. Marine Pollution, book, Fifth edition, Oxford University Press. $2005 ; 248$.

4. Latha R, Kalaivani R. Bacterial degradation of crude oil by gravimetric analysis. Advances in Applied Science Research. 2012;3(5): 2789-2795.

5. Harayama S, Kishira H, Kasai Y. Petroleum biodegradation in marine environments. Journal of molecular microbiology and biotechnology. 1999;1(1):63-70.

6. Maiti A, Das S, Bhattacharyya N. Isolation and characterization of a new bacterial strain from petroleum oil contaminated soil, India. $J$ Sci. 2012;2:103-108.

7. Mohanty M. Potential applications of biosurfactant from marine bacteria in bioremediation (Doctoral dissertation). National Institute of Technology Rourkela. 2013.

8. Osuji LC, Opiah UC. Hydrocarbon contamination of a terrestrial ecosystem: the case of Oshire-2 oil spill in Niger Delta, Nigeria. The Environmentalist. 2007;27(3):337-340. 
9. Islam MS, Tanaka M. Impacts of pollution on coastal and marine ecosystems including coastal and marine fisheries and approach for management: a review and synthesis. Marine pollution bulletin. 2004;48(7-8):624-649

10. Topham MK, Prescott SM. Diacylglycerol kinase $\zeta$ regulates Ras activation by a novel mechanism. Journal of Cell Biology. 2001. 152(6):1135-1144.

11. Pazhomand AK. Major symptoms and disease treatment (Toxicities). 1st edition. Tehran, Iran: Esharat Publications. 1997. p. 101-13.

12. Hedayati A, Vajargah MF, Yalsuyi AM, et al. Acute toxicity test of pesticide abamectin on common carp (Cyprinuscarpio). Journal of Coastal Life Medicine. 2014;2(11):841-844

13. Hedayati A, Yalsuyi AM, Vajargah MF. Acute toxicity test as a method to assessment toxicity of pollutants. Annals of Aquaculture and Research. 2017;4(1):1036.

14. Yalsuyi AM, Hedayati A, Vajargah MF, et al. Examining the toxicity of cadmium chloride in common carp (Cyprinuscarpio) and goldfish (Carassiusauratus). Journal of Environmental Treatment Techniques. 2017;5(2):83-86

15. Vignesh R, Haq MA, Srinivasan M. Biodegradation prospective of microbes. International Journal of Environmental Sciences. 2011;2(2):741-754.

16. Newman MC. Fundamentals of ecotoxicology. CRC press. 2009;458P.

17. Al-Yousuf MH, El-Shahawi MS, Al-Ghais SM. Trace metals in liver, skin and muscle of Lethrinuslentjan fish species in relation to body length and sex. Sci total environ. 2000;256(2-3):87-94.

18. Filazi A, Baskaya R, Kum C, et al. Metal concentrations in tissues of the Black Sea fish Mugilauratus from Sinop-Icliman, Turkey. Human \& experimental toxicology. 2003;22(2): 85-87.

19. Vajargah MF, Hossaini SA, Niazie EHN, et al. Acute toxicity of two pesticides Diazinon and Deltamethrin on Tench (Tincatinca) larvae and fingerling. International Journal of Aquatic Biology. 2013;1(3):138-142.

20. Vajargah MF, Yalsuyi AM, Hedayati A. Effects of dietary Kemin multienzyme on survival rate of common carp (Cyprinus carpio) exposed to abamectin. Iranian Journal of Fisheries Sciences. 2018;17(3):564-572.

21. Gingirich WH. Hepatic toxicology in fishes. In Aquatic Toxicology. ed. L. F. Weber, New York: Plenum Press. 1982; p. 55-105.

22. do CarmoLangiano V, Martinez CB. Toxicity and effects of a glyphosatebased herbicide on the Neotropical fish Prochiloduslineatus. Comparative Biochemistry and Physiology Part C: Toxicology \& Pharmacology. 2008;147(2):222-231.

23. Singh T. Removal of Petroleum Hydrocarbons by using Microbial Mats MSc thesis, National Institute of Technology Rourkela. 2011.

24. Mohsenpour R, Mousavi-Sabet H, HedayatiA, et al. In vitro effects of silver nanoparticles on gills morphology of female Guppy (Poeciliareticulate) after a short-term exposure. Microscopy Research and Technique. 2020.

25. Chorehi MM, Ghaffari H, Hossaini SA, et al. Acute toxicity of Diazinon to the Caspian vimba, Vimba vimbapersa (Cypriniformes: Cyprinidae) International Journal of Aquatic Biology. 2013;1(6):254-257.

26. Forouhar Vajargah M, Mohammadi Yalsuyi A, Hedayati A. Acute toxicity of povidone-iodine (Betadine) in common carp (Cyprinuscarpio L. 1758). Pollution. 2017;3(4):589-593.
27. Vajargah MF, Yalsuyi AM, Sattari M, et al. Effects of copper oxide nanoparticles (CuO-NPs) on parturition time, survival rate and reproductive success of guppy fish, Poecilia reticulata. Journal of Cluster Science. 2020;31(2):499-506.

28. Garapati VK. Biodegradation of Petroleum Hydrocarbons: MSc thesis,National Institute of Technology Rourkela, Odisha. 2012.

29. Swannell RP, Lee K, Mc Donagh M. Field evaluations of marine oil spill bioremediation. Microbiological reviews. 1996;60(2):342-365.

30. Vajargah MF, Hedayati A. Acute Toxicity of Butachlor to Rutilusrutiluscaspicus and Sander lucioperca in Vivo Condition. Transylvanian Review of Systematical and Ecological Research. 2017;19(3):85-92.

31. Lakshmipathy TD, Prasad AA, Kannabiran K. Production of biosurfactant and heavy metal resistance activity of Streptomyces sp. VITDDK3-a novel halo tolerant actinomycetes isolated from saltpan soil. Biol Res. 2010;4(2):108-115.

32. Tam NF, Wong TW, Wong YS. A case study on fuel oil contamination in a mangrove swamp in Hong Kong. Marine pollution bulletin. 2005;51(812):1092-1100.

33. Yalsuyi AM, Vajargah MF. Acute toxicity of silver nanoparticles in Roach (Rutilusrutilus) and Goldfish (Carassiusauratus). Journal of Environmental Treatment Techniques. 2017;5(1):1-4.

34. Forouhar Vajargah M, Mohamadi Yalsuyi A, Sattari M, et al. Acute toxicity effect of glyphosate on survival rate of common carp, Cyprinuscarpio. Environmental Health Engineering and Management Journal. 2018;5(2):61-66.

35. Mills MA, Bonner JS, Mc Donald TJ, et al. Intrinsic bioremediation of a petroleum-impacted wetland. Marine Pollution Bulletin, 2003;46(7):887899.

36. NUÑAL SN. Bioremediation of oil-contaminated seawater and sediment by an oil-degrading bacterial consortium. 2014;19(1):11-22.

37. Milić J, Beškoski V, Ilić M, et al. Bioremediation of soil heavily contaminated with crude oil and its products: composition of the microbial consortium. Journal of the Serbian Chemical Society. 2009;74(4):455460 .

38. Hassanshahian M, Emtiazi G, Kermanshahi RK, et al. Comparison of oil degrading microbial communities in sediments from the Persian Gulf and Caspian Sea. Soil and Sediment Contamination. 2010;19(3):277-291.

39. Walker SE, Dickhut RM, Chisholm-Brause C. Molecular and isotopic identification of PAH sources in a highly industrialized urban estuary. Organic geochemistry. 2005;36(4):619-632.

40. Mohsenzadeh F, Rad AC, Akbari M. Evaluation of oil removal efficiency and enzymatic activity in some fungal strains for bioremediation of petroleum-polluted soils. Iranian journal of environmental health science \& engineering. 2012;9(1):26.

41. Peebua P, Kruatrachue M, Pokethitiyook P. Histological effects of contaminated sediments in Mae Klong River tributaries, Thailand, on Nile tilapia, Oreochromisniloticus. Science Asia. 2006;32:143-150.

42. Ubalua AO. Bioremediation strategies for oil polluted marine ecosystems. Australian Journal of Agricultural Engineering. 2011; 2(6):160. 